\title{
Assessmens of the Disease Index and the Behavior of Some Peach and Nectarine Cultivars to Leaf Curl Taphrina Deformans (Berk.) Tul, in Albania.
}

\author{
Hajredin Toca ${ }^{1}$; Hekuran Vrapi ${ }^{2 *}$; Thanas Ruci ${ }^{2}$. \\ $1 *(P h D$ Candidate), Department of Plant Protection, Faculty of Agriculture and Environment, Agricultural \\ University of Tirana, Kodër Kamëz, Tirana, Albania \\ 2.Department of Plant Protection, Faculty of Agriculture and Environment, Agricultural University of Tirana, \\ Kodër Kamëz, Tirana, Albania,
}

\begin{abstract}
Leaf curl of nectarine and peach, caused by Taphrina deformans (Berk.) Tul, is a difficult disease to control throughout Albania. Heavily infected fruit trees are poorly nourished, develop fewer flower buds, and are more easily damaged from freezing in winter. In this research, susceptibility of 2 peach and 2 nectarine varieties to leaf curl disease was investigated in ecological conditions of Tirane, Albania province in 2014 and 2016. Disease severity was calculated by the 0-5 scale when typical symptoms of leaf curl were evaluated on peach and nectarine leaves in naturally infected orchards. The conditions of natural infection allowed grouping the biological material in 4 classes (plant growth stages) and 6 groups of resistance for leaf curl disease severity. From the data we see that the of disease index (Imc-ja in\%) during the three years of study varies from $4.22 \%$ in cultivar tire and reaches $22.8 \%$ in the Red Star cultivar we also comparisons this level too Control high infection which ranges from $40.66 \%$ in Roajal Black cultivar and up to $43.66 \%$ in Gomea cultivar.
\end{abstract}

Keywords: peach, organic, cultivar, quality, Taphrina deformans

\section{Introduction}

Peach is an important crop in many parts of the world. World production of peaches and nectarines stood at 21 million metric tons in 2013 (FAO, 2014). Peach and Nectarine are of the most important fruit crops in Albania. Tirana grown fruits, especially peaches, are known for their quality. Peach ranks first in local markets on Tirana. But the weather on Tirana is more moderate, with a temperature range below $2^{\circ} \mathrm{C}$ in winter and up to $35^{\circ} \mathrm{C}$ in summer. Although one well-timed spray in early spring can control the disease completely, in practice even several sprays from leaf fall until early blossom may not completely prevent leaf curl in all terminal shoots. Hasani, M. (2005). Taphrina diseases probably occur all over the world. Taphrina causes defoliation of peach trees, which may lead to small fruit or fruit drop. In plum, 50\% or more of the fruit may be affected and lost in years when the disease is severe. In both peach and plum, buds and twigs may also be affected, thus reducing the vitality of the tree significantly. In peach and nectarine, parts of or entire infected leaves are thickened, distorted, and curled downward and inward .Affected leaves at first appear reddish or purplish, but later, when the fungus produces its spores on these areas, they appear reddish yellow or powdery gray, turn yellow to brown, and drop. Blossoms, young fruit, and the current year's twigs may also be attacked. Infected blossoms and fruit generally fall early in the season. The infected twigs are swollen and stunted and die during the summer. In plum, the disease first appears on the fruit as small white blisters that enlarge rapidly as the fruit develops and soon involve the entire fruit. Agrios G.N. (2005). The fruit increases abnormally in size and is distorted, with the flesh becoming spongy. The seed ceases to develop, turns brown, and withers, leaving a hollow cavity. The fruit appears reddish at first, but later becomes gray and covered with a grayish powder. Leaves and twigs may also be affected, as in peach. Kaltani, T e B.Celo, (1992)

Taphrina diseases are controlled easily by a single fungicide spray, preferably in late fall after the leaves have fallen or in early spring before leaf buds swell. The fungicides used most commonly are the Bordeaux mixture and chlorothalonil; the latter controls the disease if applied twice, in late fall and in early spring.

\section{Materials And Methods}

Locations of experimental scheme: The experiment was set up in conjunction with the organic farm (Hajdar Kuçi) in the her field Vorë, Albania (-41 $22^{\circ} 09^{\prime \prime} \mathrm{N},-19^{\circ} 37^{\prime} 17^{\prime \prime}$ E). Experimental scheme resulted in a randomized complete block, which was designed as two factorial scheme with three repetitions.Four cultivars, two peaches, two nectarines. A total of 288 trees. Variants with 9 trees were treated.While variants with 6 trees were not treated. The scheme is also surrounded by protective belt with peaches which has undergone normal cultivation treatments. 
Plant material: The main factors in the study were: cultivars, total 4 cultivar. The main factor II was, ways of treatment. Treatments were applied at three levels: Level I with organic treatment, Level II with chemical treatment and Level III without treatment.

Plant protection products (PPP's) that were used in the scheme for 2014: At level I (organic treatment) was used preparation Sulphur 800. At level II (chemical treatment) was used triazole with getter preparation difenoconazol $* 250 \mathrm{gr} / \mathrm{L}(23.58 \% \mathrm{p} / \mathrm{p})$. Level III without treatment.

Disease assessments and times assessments: Disease assessments were made 12 days after treatment. For disease assessments, in each version with nine trees only three trees were evaluated. In variants with six trees were assessed two trees.

Visual estimation of disease severity from natural infection by Leaf curl of nectarine and peach, caused by Taphrina deformans (Berk.) Tul,, has been based on SADs (standard area diagrams) the percent of covered leaves and fruits surface occuped by the disease.(Lebeda and Widrlechner, 2003).

Table 1: Severity classes for the assessment of Leaf curl peach (Taphrina deformans) symptoms observed on leaves (expressed in percentage of leaf damage in the whole crown)

\begin{tabular}{|l|l|l|}
\hline Infection class & Leaf curl damaged leaves $(\%)$ & IT $^{*}$ \\
\hline 0 & 0 & I \\
\hline 1 & $0-5$ & VR \\
\hline 2 & $5.1-15$ & $\mathrm{R}$ \\
\hline 3 & $15.1-40$ & MR \\
\hline 4 & $40.1-60$ & MP \\
\hline 5 & $61-100$ & $\mathrm{P}$ \\
\hline
\end{tabular}

* IT = Types of infection I= Immune sustainability;), in\% Imc-ja = 0; VR = Very Resistant: Imc-ja in\% up to 5\%; $R=$ Resistant: Imc-ja in \% ranges from 5.1\% to 15\%; MR = average Resistant: IMC-ja in ranges from $15.1 \%$ to $40 \% \%$; MP = Moderately susceptible: Imc-ja in going from $40.1 \% \%$ to $60 \% ; P=$ susceptible: Imc Y.\% amounts to $60.1 \%$.

Severity and diffusion of infection were obtained by resorting to the McKinney index (McKinney, 1923) (modified from Cooke, 2006). The McKinney index (Imc) was obtained by using the following formula: where: DI (Imc) $\%=$ the total degree of infection; $n=$ infection class frequencies; $v=$ the category of infection $(0-4) ; \mathrm{N}=$ total of observed plants; $\mathrm{X}=$ highest value of the evaluation scale.

Statistical Date Analysis: Processing of data for the period of study (cultivar x method of treatment for 20142016) for all areas of the test: averages, variance and standard deviation were made using analysis of variance (ANOVA) with the statistical program ASSISTS (2016) Version 7.7 - Website http://www.assistat.com By Francisco de AS Silva DEAG-CTRN-UFC

\section{Materials And Methods}

Results on the disease index for Leaf curl peach (Taphrina deformans) during the three years of study 2014-2016 The initial data on the results achieved on the index of disease to Gjetheperdredheses peach (Taphrina deformans) with three methods of treatment (biological treatment, chemical treatment and control) and four cultivars in the study (Red Star, Venus, Roajal Black and Gomea) for three years study for 2014-2016 are given i table 1 and graph 1

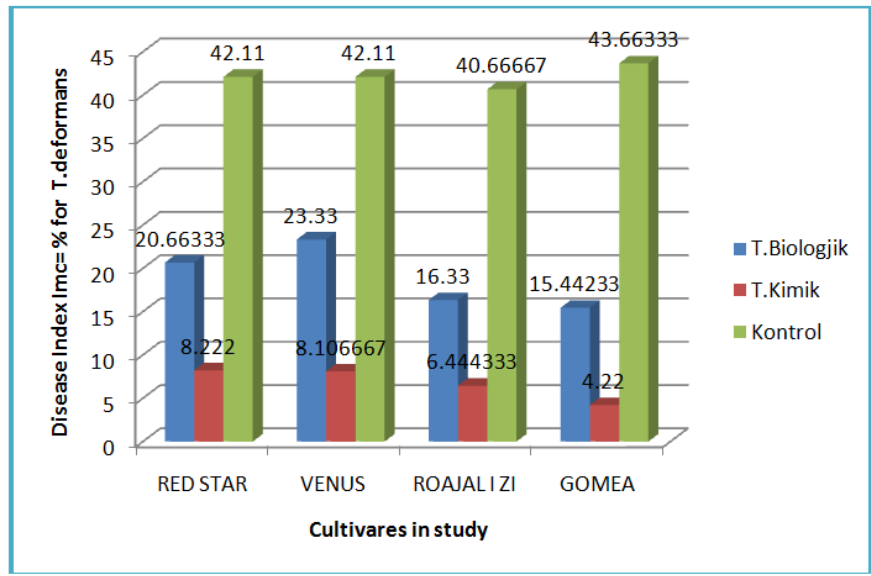

Graph 1 Disease index (Imc \%) For leaf curl the peach (Taphrina deformans) during the three years of the study from 2014 to 2016 
From the data of Table 4.1 and Figure 4.1 we see that the index of disease (ie Imc-ja in\%) during the three years of study varies from $4.22 \%$ in cultivar tire and reaches $22.8 \%$ in the cultivar Red Star we also comparisons this level too Control high infection which ranges from $40.66 \%$ in cultivar Roajal Black and up to $43.66 \%$ in cultivar rubber.Really satisfactorily results and the method given biollogike where infection (disease index) ranges from $15.4 \%$ in cultivar rubber and until 23:33 on cultivar Venus\% Factor analysis (two and three factor) by analyzing the summary table 1 on two factors (cultivars and methods of treatment) and that trefaktoriale (cultivars and methods of treatment, and years) that it analyzes and factor the third year after the psychopathology factor year is decisive the development of diseases where the weather conditions, especially temperature and humidity are determined the experiment we see that: In Table 2 are brought results of the analysis three factorial using Statistical Programme assists (2016) to two factors taken into study as cultivars with 4 levels ((Red Star, Venus, Roajal Black and Gomea), methods, treatment with 3 levels (Biological treatment, chemical treatment and control). the data of the experiment we are studying, learn that the effects of two factors cultivar (A) and treatment methods (B) are statistically high level of veracity $(p \leq 0.01)$. This is proved by the values of " $\mathrm{F}$ " for actual seizures cultivar $=4.7899 *$ which turns out to be greater than the value of "F" according to Fischer-s theoretical table where $4.7899 * *>4.7181$ per level of authenticity $<0.05$

Tabela 1. Disease index (Imc \%) For leaf curl the peach (Taphrina deformans) during the three years of the study from 2014 to 2016

\begin{tabular}{|c|c|c|c|c|c|c|c|c|}
\hline \multirow[t]{2}{*}{$\mathrm{Nr}$} & \multirow{2}{*}{$\begin{array}{l}\text { Cultivars Factor } \\
\text { (A) }\end{array}$} & \multirow{2}{*}{$\begin{array}{l}\text { Treatment } \\
\text { Factor (B) }\end{array}$} & \multicolumn{3}{|c|}{ Disease Index (Imc) in \% } & \multirow[t]{2}{*}{ Sum } & \multirow[t]{2}{*}{ Average } & \multirow{2}{*}{$\begin{array}{l}\text { Classes } \\
\text { according } \\
\text { Tukey Test }\end{array}$} \\
\hline & & & 2014 & 2015 & 2016 & & & \\
\hline & \multirow[t]{6}{*}{ Red Star } & T.Organic & 24.66 & 17 & 20.33 & 61.99 & 20.66333 & $\mathrm{~B}$ \\
\hline & & T.Chemical & 14 & 7.666 & 3 & 24.666 & 8.222 & $\mathrm{C}$ \\
\hline \multirow[t]{6}{*}{1} & & Control & 38.33 & 47.333 & 40.667 & 126.33 & 42.11 & $\mathrm{~A}$ \\
\hline & & Sum & 76.99 & 71.999 & 63.997 & 212.986 & - & \\
\hline & & Average & 25.66333 & 23.99967 & 21.33233 & - & 23.66511 & \\
\hline & & Lsd & \multicolumn{6}{|c|}{ Lsd=2.96880 për @ 0.05} \\
\hline & \multirow[t]{6}{*}{ VENUS } & T.Organic & 30.33 & 21.66 & 18 & 69.99 & 23.33 & $\mathrm{~B}$ \\
\hline & & T.Chemical & 14.66 & 6.66 & 3 & 24.32 & 8.106667 & $\mathrm{C}$ \\
\hline \multirow[t]{6}{*}{2} & & Control & 48.33 & 51.66 & 48.667 & 148.657 & 49.55233 & $\mathrm{~A}^{*}$ \\
\hline & & Sum & 93.32 & 79.98 & 69.667 & 242.967 & - & \\
\hline & & Average & 31.10667 & 26.66 & 23.22233 & - & 26.99633 & \\
\hline & & Lsd & \multicolumn{5}{|c|}{ Lsd=2.96880 për @ 0.05} & \\
\hline & \multirow[t]{6}{*}{ ROAJAL I ZI } & T.Organic & 20.66 & 14.33 & 14 & 48.99 & 16.33 & $\mathrm{~B}$ \\
\hline & & T.Chemical & 11 & 5 & 3.333 & 19.333 & 6.444333 & $\mathrm{C}$ \\
\hline \multirow[t]{6}{*}{3} & & Control & 41 & 43 & 38 & 122 & 40.66667 & A \\
\hline & & Sum & 72.66 & 62.33 & 55.333 & 190.323 & - & \\
\hline & & Average & 24.22 & 20.77667 & 18.44433 & - & 21.147 & \\
\hline & & Lsd & \multicolumn{6}{|c|}{ Lsd=2.96880 për @ 0.05} \\
\hline & \multirow[t]{6}{*}{ GOMEA } & T.Organic & 21.66 & 12 & 12.667 & 15.44233 & 15.44233 & $\mathrm{~B}$ \\
\hline & & T.Chemical & 6 & 4.66 & 2 & 4.22 & 4.22 & $\mathrm{C}$ \\
\hline \multirow[t]{4}{*}{4} & & Control & 42.33 & 47.66 & 41 & 43.66333 & 43.66333 & A \\
\hline & & Sum & 23.33 & 21.44 & 18.55567 & 21.10856 & - & \\
\hline & & Average & 23.33 & 21.44 & 18.55567 & - & 21.10856 & \\
\hline & & Lsd & \multicolumn{6}{|c|}{ Lsd=2.96880 për @ 0.05} \\
\hline
\end{tabular}

*The Tukey Test at a level of $5 \%$ of probability was applied The averages followed by the same letter do not differ statisticaly between themselves

Like wise for treatment methods where the values of "F" for actual -ve $=249.5199 * *$ treatment methods which turns out to be greater than the value of "F" according to Fischer-s theoretical table where $249.5199 * *>5.6136$ per level authenticity $<0.001$ The effect of interaction (AXB) then (cultivar $\mathrm{x}$ treatment method) are not confirmed as the years take as repetition where the values of " $\mathrm{F}$ " for actual seizures (cultivar $\mathrm{x}$ treatment method) $=0.5959$ ns.

Tabela 2 Analysis of variance MANOVA Two factorial for the disease Index leaf curl peach to three methods of treatment and four cultivars in the study; (Red Star). (Venus). (Roajal black). (Gomea)

\begin{tabular}{|l|l|l|l|l|}
\hline Variation Source & Df* & $\begin{array}{l}\text { Square } \\
\text { Sum }\end{array}$ & $\begin{array}{l}\text { Mean } \\
\text { Square }\end{array}$ & $\begin{array}{l}\text { F=Statistics of the } \\
\text { test }\end{array}$ \\
\hline Cultivaret (A) & 3 & 258.9044 & 86.30145 & $4.7899 * *$ \\
\hline Methods of treatment (B) & 2 & 8991.415 & 4495.7 & $249.5199 * *$ \\
\hline Int AxB & 6 & 64.41699 & 10.73617 & $0.5959 \mathrm{~ns}$ \\
\hline Treatments & 11 & 9314.736 & 846.7942 & $46.9986 * *$ \\
\hline Error & 24 & 432.4184 & 18.01743 & \\
\hline Total Variation & 35 & 9747.155 & & \\
\hline
\end{tabular}


$* D f=$ Degree of freedom $\quad * *$ Significative at a level of $1 \%$ of probability $(\mathrm{p}<.01) \quad *$ Significative at a level of $5 \%$ of probability $(.01=<p<.05)$ ns Non-significative ( $p>=.05)$

Table 3 bring three factorial analysis results using the Statistical Program assists (2016) to three factors taken into study as:

- A factor levels in three years (three years of study in 2014, 2015, 2016).

- Factor $\mathrm{B}=4$ level varieties (cultivars $=$ Red Star, Venus, Roajal Black and Gomea).

- Factor $\mathrm{C}=3$ levels with treatment methods (biological treatment, chemical treatment and control.

Tabela 3 Analysis of variance MANOVA for the diseaseIndex for leaf curl peach to three methods of treatment and four cultivars in the study; (Red Star). (Venus). (Roajal black). (Gomea) during the three years of the study from 2014 to 2016

\begin{tabular}{|l|l|l|l|l|l|}
\hline Variation Source & Df* & Square Sum & Mean Square & $\begin{array}{l}\text { F=Statistics of the } \\
\text { test }\end{array}$ & $\begin{array}{l}\text { Variation } \\
\text { Source }\end{array}$ \\
\hline Years (A) & 2 & 583.685 & 291.842 & $36.3541 * *$ & $>0.050$ \\
\hline Cultivars (B) & 3 & 627.138 & 209.046 & $26.0404 * *$ & $>0.050$ \\
\hline Methods of treatment C & 2 & 25968.57 & 12984.28 & $1617.41 * *$ & $<0.001$ \\
\hline Int AxB & 6 & 40.16 & 6.6944 & $0.8339 \mathrm{~ns}$ & $>0.050$ \\
\hline Int AxC & 4 & 602.37 & 150.592 & $18.7589 * *$ & $<0.010$ \\
\hline Int BxC & 6 & 249.94 & 41.657 & $5.1892 * *$ & 0.0298 \\
\hline Int AxBxC & 12 & 145.33 & 12.11 & $1.5087 \mathrm{~ns}$ & $>0.050$ \\
\hline Treatments & 35 & 28217.21 & 806.20 & $100.4271 * *$ & $<0.001$ \\
\hline Error & 72 & 578.00 & 8.027 & & \\
\hline Total Variation & 107 & 28795.21 & & & \\
\hline
\end{tabular}

$* \mathrm{Df}=$ Degree of freedom **: E vertetuar per niveline propabilitetit $1 \%(\mathbf{p}<\mathbf{0 . 0 1}) ; *$ : $\mathbf{E}$ vertetuar per niveline propabilitetit 5\% $(0.01=<p<0.05)$; NS: Pa vertetesi te propabilitetit $(p>=0.05)$. Sipas testit Tukey Kramer

The data of the experiment we are studying, learn that the effects of three factors. A factor levels in three years (three years of study in 2014, 2015, 2016). Factor B $=4$ level varieties (cultivars $=$ Red Star, Venus, Roajal Black and rubber) and factor $\mathrm{C}=3$ levels with treatment methods (biological treatment, chemical treatment and control) have been confirmed statistically high level of veracity $(p \leq 0: 01)$.

Where "F" for Factor A factual IMF Years $=36.3541 * *$ is greater than both "F" theoretical th to two levels of authentication $\mathrm{P}=\mathrm{P}=0: 05$ and 0:01 (6944 and 18).

Where "F" for Factor B factual IMF cultivar $=26.0404 * *$ is greater than both "F" theoretical th to two levels of authentication $\mathrm{P}=\mathrm{P}=$ 0:05 and 0:01 (6944 and 18).

Where "F" factual IMF for Factor $\mathrm{C}=1617.41 * *$ treatment methods is greater than both "F" theoretical th to two levels of authentication $\mathrm{P}=\mathrm{P}=0: 05$ and 0:01 (6944 and 18).

Likewise the table and see that the effects of interaction Interaction A x C and B x C Interaction been proven statistically high level of veracity $(\mathrm{p} \leq 0: 01)$.

Where "F" factual IMF for Interaction A x C $=18.7589 * *$ is greater than both " $F$ " theoretical th to two levels of authentication $\mathrm{P}=0.05$ and $\mathrm{P}=0.01$ (6944 and 18).

Where "F" for Interaction IMF factual B x C $=5.1892 * *$ is greater than both "F" theoretical th to two levels of authentication $\mathrm{P}=\mathrm{P}=0: 05$ and 0:01 (6944 and 18).

The fact that the interaction between a factor and factor B Where "F" factual IMF for Interaction A x B = 0.8339 ns indicates that there three years in treatment methods

\section{Conclusion}

The data of the experiment we are studying, learn that the effects of three factors. A factor levels in three years (three years of study in 2014, 2015, 2016). Factor B $=4$ level varieties (cultivars $=$ Red Star, Venus, Roajal Black and rubber) and factor $\mathrm{C}=3$ levels with treatment methods (biological treatment, chemical treatment and control) have been confirmed statistically high level of veracity ( $p \leq 0: 01)$. From the data we see that the index of disease (ie Imc-ja in \%) during the three years of study varies from $4.22 \%$ in cultivar tire and reaches $22.8 \%$ in the cultivar Red Star we also comparisons this level too Control high infection which ranges from $40.66 \%$ in cultivar Roajal Black and up to $43.66 \%$ in cultivar rubber. Really satisfactorily results and the method given biollogjike where infection (disease index) ranges from 15.4\% in cultivar rubber and until 23:33 on cultivar Venus\% 


\section{References}

[1]. Food and Agriculture Organisation (FAO) of the United Nations. 2014. Agricultural Statistics and Database. FAO Headquarters. Rome, Italy.

[2]. Agrios G.N. (2005). Plant Pathology. Fifth Edition. Elsevier Academic . New York.

[3]. Hasani, M. (2005). Sëmundjet e Pemëve frutore. Tiranë.

[4]. Kaltani, T e B.Celo, (1992). "Fitopatologjia bujqësore'"- Pjesa e përgjithshme dhe e veçantë.

[5]. Cooke, B. M. (2006). Disease assessment and yield loss. In: The Epidemiology of Plant Diseases. B. M. Cooke, D. Gareth Jones and B. Kaye (Eds.) Second edition. The Netherlands: Springer.f.61.

[6]. Mckinney H.H. (1923). Influence of soil temperature and moisture on infection of wheat seedlings by Helminthosporium sativum. Journal Agricultural Research, 26:195-217.

[7]. J. Phytopathol160:647-654 (2012) Population Structure and Managementof Podosphaera pannosa Associated with Peach Powdery Mildew in Oman. Abdullah M. Al-Sadi1, Ibtihal J. Al-Raisi 2, Masood Al-Azri2, Hamoud Al-Hasani2, Mohammed S. AlShukaili2,Saif M. Al-Shuraiqi 2, Khater O. Al-Fahdi2 and Mike L. Deadman.

[8]. Powdery mildews of stone fruit crops.(2010) Ramesh Pokharel and Harold Larsen, Colorado State University, USA.

[9]. Programi statistikor ASSISTAT (2014) Version 7.7 -Website http://www.assistat.com By Francisco de A. S. e Silva DEAGCTRN-UFC. 